\title{
Wave energy and hot spots in Anzali port
}

\author{
Sanaz Hadadpour, MSc \\ School of Civil Engineering, Iran University of Science and Technology, Tehran, Iran \\ Amir Etemad-Shahidi, PhD* \\ Griffith School of Engineering, Gold Coast Campus, Griffith University, QLD, 4227 \\ Ebrahim Jabbari, PhD \\ School of Civil Engineering, Iran University of Science and Technology, Tehran, Iran \\ Bahareh Kamranzad, PhD \\ Ocean Engineering and Technology Research Center, Iranian National Institute for \\ Oceanography and Atmospheric Science, Tehran, Iran \\ *Corresponding Author, E-mail: a.etemadshahidi@griffith.edu.au \\ Tel: +61 075552 9267, Fax: +61 0755528065
}

\begin{abstract}
:
Providing energy without unfavorable impacts on the environment is an important issue for many countries. Wave energy is one of the renewable resources with high potential and low impact on the environment, especially in coastal regions. The estimation of the wave characteristics is essential for selection of the appropriate location for wave energy exploitation. In this study, SWAN was used for modeling of the wave characteristics and to describe the existence and variability of wave energy in the southern part of the Caspian Sea. The model results were calibrated and verified using in-situ buoy measurements. Wave parameters were simulated and the annual wave energy was estimated in the study area. Then, high-energy spots were determined and the monthly average wave energy and seasonal variations of wave energy in the selected site were investigated. Furthermore, wave energy resource was characterized in terms of sea state parameters i.e. significant wave heights,
\end{abstract}


wave periods and mean directions for selecting the most appropriate wave energy converters in the selected site. It was found that January and February, i.e. winter months, are the most energetic months and the main wave directions with the highest frequencies are NE and NNE in this site.

Keywords: Renewable energies, Wave energy, Anzali, SWAN, QuikSCAT wind field

\section{Introduction}

Due to the limitation of the fossil fuels and their negative environmental impacts, several researches have been conducted on development of the renewable resources. Therefore, conventional energy resources can be substituted with different kinds of renewable energy resources such as solar, wind and ocean energy (i.e. waves, tides, marine currents and thermal gradients). Among the various clean and green renewable energy resources, wave energy is known as an energy resource with limited negative impacts and the highest energy density [13]. The global wave energy potential has been evaluated between 1 and 10 TW, which is comparable with world energy demand [4]. There are several studies in literature, which have assessed the wave energy resources in different regions of the world. The aforementioned studies covered areas with the potential of energy extraction such as Argentina [5], Portugal [6,7], Sweden [8,9], US [10-13], UK [14], Taiwan [15], Australia [16], Spain [17-19], South Korea [20] and Black Sea [21].

Considering the construction and operational costs of the wave energy converters (WECs), the economics dictates the most appropriate sites for wave farms [14,17]. Iglesias and Carballo [17,18] and Saket and Etemad-Shahidi [22] investigated the wave energy 
characteristics, in terms of sea states, which are important for selecting the most appropriate WEC with maximum efficiency.

As there are long coastlines in Iran and because of increasing energy needs, due to the population growth and also improving living conditions, wave energy can be used as a new resource in this country. As well as evaluating the wave energy potential in some coastal areas of the Iranian seas [22,23], the long term variation of wave power was investigated along the southern coasts of Iran [24].

Since recording wave data over a long period of time is challenging and expensive, there is lack of such data in most regions. Hence, wave parameters can be obtained using wave simulations. In this regard, different approaches including empirical-based, soft computingbased and numerical-based models have been utilized [25-29]. In this study, the wave energy climate along the south-western part of the Caspian Sea was investigated. For this purpose, one of the most popular numerical models, Simulating Waves Nearshore (SWAN) model [30-33] forced by QuikSCAT wind field has been implemented for simulating the wave parameters. Collected wave data by Anzali buoy were used for the calibration and verification of the numerical model.

The annual and seasonal mean wave energies were calculated using simulated wave parameters in the study area. Afterwards, the high energy spots were specified and the most appropriate site for wave energy extraction, considering their distance from coastline and water depth, was determined. The seasonal and monthly variations of wave energy were investigated in the selected site. In addition, the wave energy resource was characterized in terms of significant wave heights, peak periods and mean directions to determine the most efficient wave energy converter in the selected site. 


\section{Materials and Methods}

\subsection{Area of interest and availability of data}

The Caspian Sea was chosen for this study and the area of interest is Anzali port which is located in the south-western part of it (Figure 1). Caspian Sea with a surface area of 371,000 $\mathrm{km}^{2}$ is the world's largest lake. It is bordered to the northwest by Russia, to the west by Azerbaijan, to the south by Iran, to the southeast by Turkmenistan, and to the northeast by Kazakhstan. This area is rich in energy wealth as well as economic activities. Hence, it is considered as an area where the investigation of providing energy is very important.

The accuracy of numerical models mainly depends on the quality of the used wind data. Therefore, using an appropriate wind field is essential for wave modeling and simulation [3437]. In this study, QuikSCAT wind field was used as input to develop the SWAN model.

The NASA's QuikSCAT satellite, launched in 1999, can provide wind vector measurements over global oceans with considerable reliability and sufficient time frequency. The QuikSCAT wind product has the spatial and temporal resolutions of $25 \mathrm{~km}$ and 12 hours, respectively. Wind data measured by the satellite sensors are mapped based on ascending and descending passes, which are then combined to provide daily wind maps [38]. The period of data collection template was repeated every four days. The closest hours to the measured data by QuikSCAT were chosen as 2:00 and 14:00 in the Caspian Sea.

Based on the QuikSCAT manual [38], the root mean square error (RMSE) is about 20 degrees in wind direction for wind speed ranging from 3-30 m/s and $2 \mathrm{~m} / \mathrm{s}$ in wind speed for the range 3-20 m/s. At first glance, the uncertainties of QuikSCAT wind measurements seem to be large. However, it should be noted that usually wind speeds larger than $10 \mathrm{~m} / \mathrm{s}$ 
contribute to wave growth and development. In addition, wave energy is assessed and averaged over periods of months or years. Therefore, the uncertainty in the average wave energy is much smaller than that of QuikSCAT wind measurements. In other words, the possible error due to the inaccurate wind measurements will be reduced when (long period) averaged wave energy are of interest. Moreover, the QuikSCAT satellite measures the wind speed on $10 \mathrm{~m}$ level above the sea surface. The data collected by QuikSCAT satellite in the Caspian Sea had some gaps. Hence, the average values of the closest adjacent nodes (spatial interpolation) were used to fill the gaps in the wind data.

Significant wave height and peack period, collected by Anzali buoy $\left(49.52^{\circ} \mathrm{E}\right.$ and $\left.37.549^{\circ} \mathrm{N}\right)$ (Figure 1), were used for calibration and verification of the model. This buoy was deployed by Ports and Maritime Organization (PMO) where the water depth was about $72.8 \mathrm{~m}$ there. The wave data, including significant wave height and peak period were recorded hourly from May to June, 2003 with some gaps. In addition, the model bathymetry input was set based on the data from GEOphysical DAta System (GEODAS) (Figure 2).

\subsection{Model description}

In this research, SWAN model [31,32,39,40,41], which is a third generation fully spectral wind wave model, was utilized for wave simulation. The SWAN model is based on action density spectrum $N(\sigma, \theta)$ rather than energy density $E(\sigma, \theta)$, as action density is conserved in the presence of currents whereas energy density is not. Action density is stated as follow [31]:

$N(\sigma, \theta)=E(\sigma, \theta) / \sigma$ 
where $\theta$ is the wave propagation direction and $\sigma$ is the relative radian frequency. The basic equation of SWAN model is spectral action balance equation for the Cartesian coordinates, defined as [32]:

$\frac{\partial}{\partial t} N+\frac{\partial}{\partial x} C_{x} N+\frac{\partial}{\partial y} C_{y} N+\frac{\partial}{\partial \sigma} C_{\sigma} N+\frac{\partial}{\partial \theta} C_{\theta} N=\frac{S}{\sigma}$

where $N$ represents the temporal change of action density, and $C_{x} N$ and $C_{y} N$ are the propagation of action in $\mathrm{x}$ and $\mathrm{y}$-spaces, respectively. The $C_{\sigma}$ illustrates the shifting of the relative frequency due to variations in depth and currents. $C_{\theta}$ demonstrates the depth-induced and current-induced refraction. In which, $C$ is the propagation velocity of wave action in spectral $(\sigma, \theta)$ and geographical $(x, y)$ spaces. The term $S$, which is a function of $\sigma, \theta, x, y$ and $t$, shows the effects of generation, dissipation and also nonlinear wave-wave interactions [32].

SWAN cycle III version 40.72AB [33] was used in 2-dimensional nonstationary mode in this study. Moeini and Etemad-Shahidi [42] showed that the formulation for wind input parameterization developed by Komen et al. [43] leads to a more accurate prediction of significant wave height. Hence, the theory of Komen et al. [43] was used for the exponential wind input growth in the simulation. The quadruplet nonlinear interactions with default values was activated in the computations. Therefore, dissipation due to bottom friction, depth-induced wave breaking and whitecapping were considered in the simulations.

A uniform, regular computational grid with $0.01^{\circ}$ resolutions in $\mathrm{x}$ and $\mathrm{y}$ directions was specified for the SWAN model. The bathymetry had a resolution of $0.0166^{\circ} \times 0.0166^{\circ}$ with $480 \times 710$ uniform cells in $x$ and $y$ directions, respectively. The number of uniformly distributed directions and frequencies of the spectral space were 18 and 20, respectively. In addition, the model time step was set as 10 minutes by trial and error. 


\subsection{Computation of wave energy}

Different methods have been studied by Ertekin and Yingfan [44] for estimating the wave power. However, the most common method is wave power estimation using significant wave height and period [3]. The total wave energy density including potential and kinetic is [16]:

$$
E=\frac{1}{16} \rho g H_{s}^{2}
$$

Where $\rho$ is the sea water density $(1025 \mathrm{~kg} / \mathrm{m}), g$ is the gravity acceleration $\left(9.81 \mathrm{~m} / \mathrm{s}^{2}\right)$ and $H_{s}$ is the significant wave height (m). Irregular ocean waves can be modelled as a summation of numerous regular wave components. Therefore, the sea surface is composed of waves with different characteristics. In order to compute the wave energy resource, two wave spectral parameters (i.e. significant wave height and energy period) are used [45]. The wave power per unit width of the progressing waves in deep water is given as follow [23]:

$$
J=\frac{\rho g^{2}}{64 \pi} H_{s}^{2} T_{e}=0.49 H_{s}^{2} T_{e}
$$

In which $J$ is the wave power of the crest length $(\mathrm{kW} / \mathrm{m})$ and $T_{e}$ is the energy period (s). Energy period $\left(T_{e}\right)$ is equal to peak period $\left(T_{p}\right)$ multiplied by a factor, which is equal to 0.9 if the standard JONSWAP spectrum with a peak enhancement factor of $\gamma=0.33$ is assumed [23]. Wave data obtained from the SWAN model were used to estimate the wave energy in the study area using this method.

2.4. Validation of the wave model 
Wave data recorded from Anzali buoy between May 23 to May 27, 2003 were used to calibrate the SWAN model. The model calibration was carried out based on the minimization of simulation error of significant wave height. Since the sensitivity analysis showed that the effect of whitecapping rate is more important than depth-induced wave breaking and bottom friction coefficients on the wave simulation, it was used as tunable parameter for model calibration. The calibrated model was verified using the in-situ measured data from June, 15th to June, 21st, 2003. Comparison of the time series of the measured and modeled wave height and power during the calibration and verification periods are illustrated in figures 3 and 4, respectively. As seen, there is a good agreement between the measured and modeled data in these periods. Statistical similarity was checked for these intervals (Table 1). Although the model was calibrated using the measurements in May, it was observed that waves in June were accurately simulated. In addition, some error metrics for quantitative evaluation of the models' performance were used. These include Bias, correlation coefficient (R) and RMSE given as:

Bias $=\bar{y}-\bar{x}$

$R=\frac{\sum_{i}\left(\left(x_{i}-\bar{x}\right) \times\left(y_{i}-\bar{y}\right)\right)}{\sqrt{\sum_{i}\left(x_{i}-\bar{x}\right)^{2} \sum_{i}\left(y_{i}-\bar{y}\right)^{2}}}$

$R M S E=\sqrt{\frac{\sum_{i}^{N}\left(x_{i}-y_{i}\right)^{2}}{N}}$

where $x_{i}$ denotes the measured data and $y_{i}$ represents the modeled data. $\bar{x}$ and $\bar{y}$ are the mean value of measured and modeled data, respectively and $N$ shows the total number of data. The error indices for both calibration and verification periods are listed in Table 2. 
According to the Bias, the wave height and power calculated using SWAN estimates and buoy recorded data are nearly similar. The high values of correlation coefficient for wave parameters, which are about 0.9 for both calibration and verification periods, imply that the model performs well in simulation of wave parameters. In addition, considering the RMSE values, the SWAN model has the ability of wave simulation in the study area, so it can be used to simulate the wave condition in the whole computational grid.

\section{Results and discussions}

\subsection{Wave energy estimation}

After validating the wave model, simulated wave data were used to estimate the wave energy in the study area. For this purpose, the average wave power for the year 2003 was calculated from simulated time series of wave characteristics (i.e. significant wave height and peak period) using equation 4. The spatial distribution of annual wave power is indicated in Figure 5 showing the highest average wave power in the eastern part of the study area which is near to the central part of the Caspian Sea. This is mainly because of the long fetch length part of this area. It was found that the average wave power resource ranges from 0.5 to $1 \mathrm{~kW} / \mathrm{m}$ in the western and eastern parts of the study area, respectively. The average wave intensity of the Caspian Sea is low compared to those of open oceanic locations. This is mainly because the Caspian Sea is an enclosed water basin. However, the vicinity of the selected area to the Anzali port, its appropriate water depth and distance from the coastline are the other points that need to be considered $[14,17,46]$. More research is required on the improvement of WEC efficiency, especially in low intensity wave energy environments. 
Since the weather condition affects wave conditions such as wave height and energy, seasonal wave energy changes were also investigated. Figure 6 shows the average seasonal spatial distributions of wave power. It can be seen that the lowest powers exist in summer and autumn, whereas spring and winter seasons have higher wave powers. Moreover, waves are more energetic in winter in comparison with other seasons. The values of wave power in winter are about 2.5 times higher than those in summer. Besides, the overall comparison shows similar wave power patterns for both summer and autumn. In these seasons, average wave powers range from 0.2 to $0.8 \mathrm{~kW} / \mathrm{m}$ in the whole study area. In addition, the seasonal and annual average wave energies show the same hot spots where more energetic waves occur in the eastern part of the study area in comparison to other parts.

\subsection{Hot spots}

After estimation of the wave power in the whole study area, locations with the highest wave power were determined (Figure 7). Table 3 reports the location of the selected sites, their annual wave power, and distance from the coastline and water depth. In order to select a suitable area for installation of the wave energy converter, the construction and operational costs should be considered as well as the wave resource availability [12]. Taking into consideration the important factors such as the proximity to the cities and other aforementioned factors, site $\mathrm{M}$ is suggested as the most appropriate area for the installation of a wave farm.

After determining the annual variations of wave power in the study area and selecting the most appropriate site for a wave farm (site $\mathrm{M}$ ), the seasonal and monthly variations of wave power were also analyzed in this site (Figure 8). As seen, the winter is the most energetic 
season and the mean wave power during this season is nearly two times of those of other seasons. Moreover, the monthly averaged wave power ranges from 0.45 to $2.3 \mathrm{~kW} / \mathrm{m}$ and the highest energy exist in January and February. Furthermore, the wave directions in site M were investigated to find how wave directions vary during January and February. The wave roses of these two energetic months for site $M$ are shown in Figure 9. From this figure, the dominant wave directions are determined to be NE and NNE.

\subsection{Characterization of the wave energy potential}

The characterization of wave energy potential is of central importance for selecting the most appropriate wave energy converter (WEC). This is because of the fact that the WECs efficiency depends on the ranges of wave heights and periods. Therefore, the distributions of the significant wave height and peak period were considered in six and eight intervals, respectively. Table 4 shows the results of wave characteristics analysis with wave energy values expressed in $\mathrm{kWh} / \mathrm{m}$ and also the percentage of the accessible total energy for each interval.

According to this table, the waves with heights less than $2 \mathrm{~m}$ and peak period between 4 and $7 \mathrm{~s}$ have the highest frequencies, but the bulk of energy is associated with higher waves with higher periods and lower probabilities of occurrence. Therefore, the selection of WECs should aim to maximum efficiency in the ranges less than $2 \mathrm{~m}$ in terms of significant wave height and between 4 and $7 \mathrm{~s}$ in terms of peak period. Noting that there are few cases of reasonable efficiency in this range, future development of WEC may be required for this wave amplitude range. 
Babarit et al. [47] recently investigated eight existing WEC's and compared their performance at five locations with different annual wave power. They used different performance measures and showed that the annual absorbed energy per characteristic mass of different devices are more or less the same and the variation of annual absorbed wave energy mostly depends on the selected site. Their numerical simulations also revealed that a bottomfixed oscillation flap has the highest absorbed energy per area in low energetic environments. Considering the wave climate of the Port of Anzali, this type of WEC's can be a more suitable candidate. It should be noted that the amount of wave energy varies and annual means just allow a rough estimation of the actual power output of WECs. For a precise evaluation, it is indispensable to consider either seasonal or monthly variations of the wave energy resources. Any plans for prospective exploitation of the wave energy resources can be affected by temporal and seasonal variability of wave characteristics.

The dominant wave direction is an important factor in design of a wave energy converter. Hence, annual wave energy direction was investigated and the combination of significant wave height intervals and mean wave directions of site $\mathrm{M}$ is depicted in Table 5. Similar to figure 9, the main directions with the highest probabilities of occurrence for the whole year are NE and NNE. Table 5 shows that the prevailing wave direction for selecting the appropriate WEC corresponds well to NE direction.

Figure 10 shows the contribution of the different sea states to the total annual energy at site M. Sea states are classified into virtual squares which their colours representing the contribution of each bin to the total annual wave energy. Wave energy is centralized for peak periods between $4.5 \mathrm{~s}$ and $6.5 \mathrm{~s}$ and for significant wave height less than $1.5 \mathrm{~m}$. 


\section{Summary and conclusions}

This study represents an assessment of the wave energy along the south-western part of the Caspian Sea, near Anzali port, which is located in the north of Iran. This geographical area was selected as the Anzali port is the main port of Iran in the Caspian Sea. Access to new resources of energy is vital for the future development plan of this port. To achieve this, a popular numerical model, i.e., SWAN was used to simulate the wave characteristics. Due to the importance of wind field in SWAN model, QuikSCAT wind data were used as input parameter. One of the draw backs of the current study is the uncertainty of the model input data, especially the wind speed. For a wind speed of $10 \mathrm{~m} / \mathrm{s}$, the uncertainty of the wind speed is about $20 \%$. This may lead to $50 \%$ inaccuracy in the estimated energy of singular events. However, when averaged over periods of months or seasons, the level of uncertainty becomes much smaller and comparable to that of climate variability. In order to validate the model, the numerical data series of wave characteristics were compared with buoy recorded data. Similar to previous wave modeling studies (e.g. [26-28]), a relatively short period of data collection was used for the verification of SWAN. Although the model was calibrated using the data obtained in May, it was observed that larger waves in June were accurately modeled (Figure 4). This implies that that the model is capable of simulating higher waves and can be used for modeling of wave characteristics in other seasons. The validated model was performed to simulate the time series of significant wave height and peak period for year 2003. Then, the time series of wave power were obtained from these parameters. The spatial distribution of annual and seasonal wave power were plotted for the study area. The results showed that the wave power in the eastern part of the study area is up to $70 \%$ higher than that of the western part. Moreover, the mean annual wave power in the study area varies from 0.2 to $1.2 \mathrm{~kW} / \mathrm{m}$. Analysis of the seasonal variations showed that higher wave energy is mostly 
available in winter, followed by spring and the lowest wave energy occurs in summer and autumn.

Additionally, energy resource in the selected sites with the highest wave energy was analyzed. Taking into account the important factors such as water depth, distance from coastline as well as annual wave power amount, easternmost area was found to be the most appropriate site for wave energy extraction. Beside, the seasonal and monthly variations of wave power in this site were investigated. It was found that waves with the highest energy occur during winter, followed by spring. Also, January and February, i.e. winter months, are identified as the most energetic months in the study area. Wave directions in these two months show that the prevailing wave direction changes from NNE in January to NE in February.

In addition, the wave energy resource was characterized in terms of significant wave heights and peak periods. It was found that the waves with significant wave height less than $2 \mathrm{~m}$ and peak period between 4 and $7 \mathrm{~s}$ have the highest frequency. However, most of the energy is provided by waves with a significant wave height less than $1.5 \mathrm{~m}$ and peak periods between 4.5 and 6.5 s. Therefore, these ranges of wave characteristics should be considered to select the WECs to supply maximum efficiency. Finally, quantitative comparison of the wave directions and frequencies showed that the prevailing wave directions with the highest frequencies are NE and NNE.

\section{Acknowledgement}

The authors are grateful to Ports and Maritime Organization (PMO) for providing the measured data of buoy and to JPL PO.DAAC for the QuikSCAT wind data. The SWAN 
group at Delft University of Technology is also thanked for providing the numerical model. Dr. Mohammad Nikkhoo is appreciated for his helpful comments. 


\section{References}

[1] Clément AH, McCullen P, Falcão A, Fiorentino A, Gardner F, Hammarlund K, et al. Wave energy in Europe: current status and perspectives. J Renew and Sustain Energy Rev 2002; 6(5): 405-431.

[2] Leijon M, Bernhoff H, Berg M, Ågren O. Economical considerations of renewable electric energy production-especially development of wave energy. J Renew Energy 2003; 8: 1201-1209.

[3] Henfridsson U, Neimane V, Strand K, Kapper R, Bernhoff H, Danielsson O, Leijon M, Sundberg J, Thorburn K, Ericsson E, Bergman K. Wave energy potential in the Baltic Sea and the Danish part of the North Sea, with reflections on the Skagerrak. J Renew Energy 2007; 32: 2069-2084.

[4] Panicker NN. Power resource potential of ocean surface wave. In: The Wave and Salinity Gradient Workshop, Newark, Delaware, USA, 1976, p. 1-48.

[5] Lanfredi NW, Pousa JL, Mazio CA, Dragani WC. Wave-power potential along the coast of the province of Buenos Aires, Argentina. J Energy 1992; 17: 997-1006.

[6] Pontes MT, Aguiar R, Pires HO. A nearshore wave energy atlas for Portugal. J Offshore Mech Arctic Eng 2005; 127: 249-255.

[7] Rusu E, Guedes Soares C. Numerical modelling to estimate the spatial distribution of the wave energy in the Portuguese nearshore. J Renew Energy 2009; 34: 1501-1516.

[8] Bernhoff H, Sjostedt E, Leijon M. Wave energy resources in sheltered sea areas: a case study of the Baltic Sea. J Renew Energy 2006; 31: 2164-2170.

[9] Waters R, EngstrÖm J, Isberg J, Leijon M. Wave climate off the Swedish west coast. J Renew Energy 2009; 34: 1600-1606.

[10] Wilson JH, Beyene A. California wave energy resource evaluation. J Coast Res 2007; 23: 679-690. 
[11] Stopa JE, Cheung KF, Chen YL. Assessment of wave energy resources in Hawaii. J Renew Energy 2011; 36: 554-567.

[12] Lenee-Bluhm P, Paasch R, Özkan-Haller HT. Characterizing the wave energy resource of the US Pacific Northwest. J Renew Energy 2011; 36: 2106-2119.

[13] Defne Z, Haas KA, Fritz HM. Wave power potential along the Atlantic coast of the southeastern USA. J Renew Energy 2009; 34: 2197-2205.

[14] Folley M, Whittaker TJT. Analysis of the nearshore wave energy resource. J Renew Energy 2009; 34: 1709-1715.

[15] Chen F, Lu SM, Tseng KT, Lee SC, Wang E. Assessment of renewable energy reserves in Taiwan. J Renew and Sustain Energy Rev 2010; 14: 2511-2528.

[16] Hughes MG, Heap AD. National-scale wave energy resource assessment for Australia. J Renew Energy 2010; 35: 1783-1791.

[17] Iglesias G, Carballo R. Wave energy and nearshore hot spots: the case of the SE Bay of Biscay. J Renew Energy 2010; 35: 2490-2500.

[18] Iglesias G, Carballo R. Wave energy resource in the Estaca de Bares area (Spain). J Renew Energy 2010; 35: 1574-1584.

[19] Iglesias G, Carballo R. Wave power for La Isla Bonita. J Energy 2010; 35: 5013-5021.

[20] Kim G, Jeong WM, Lee KS, Jun K, Lee ME. Offshore and nearshore wave energy assessment around the Korean Peninsula. J Energy 2011; 36: 1460-1469.

[21] Akpinar A, Komurcu MI. Assessment of wave energy resource of the Black Sea based on 15-year numerical hindcast data. J Appl Energy 2013; 101: 502-512.

[22] Saket A, Etemad-Shahidi A. Wave energy potential along the northern coasts of the Gulf of Oman. J Renew Energy 2012; 40: 90-97.

[23] Abbaspour M, Rahimi R. Iran atlas of offshore renewable energies. J Renew Energy 2011; 36: 388-398. 
[24] Kamranzad B, Chegini V, Etemad-Shahidi A. Assessment of wave energy variation in the Persian Gulf. J Ocean Eng 2013; 70: 72-80.

[25] Mahjoobi J, Etemad-Shahidi A, Kazeminezhad MH. Hindcasting of wave parameters using different soft computing methods. J Appl Ocean Res 2008; 30: 28-36.

[26] Moeini MH, Etemad-Shahidi A, Chegini V. Wave modeling and extreme value analysis off the northern coast of the Persian Gulf. J Appl Ocean Res 2010; 32: 209-218.

[27] Moeini MH, Etemad-Shahidi A, Chegini V, Rahmani I. Wave data assimilation using a hybrid approach in the Persian Gulf. J Ocean Dyn 2012; 62: 785-797.

[28] Moeini MH, Etemad-Shahidi A, Chegini V, Rahmani I, Moghaddam M. Error distribution and correction of the predicted wave characteristics over the Persian Gulf. J Ocean Eng 2014; 75: 81-89.

[29] Kamranzad B, Etemad-Shahidi A, Kazeminezhad MH. Wave height forecasting in Dayyer, the Persian Gulf. J Ocean Eng 2011; 38: 248-255.

[30] Holthuijsen LH, Booij N, Herbers THC. A prediction model for stationary, short-crested waves in shallow water with ambient currents. J Coast Eng 1989; 13: 23-54.

[31] Booij N, Ris RC, Holthuijsen LH. A third-generation wave model for coastal regions. 1. Model Description and validation. J Geophys Res 1999; 104: 7649-7666.

[32] Ris RC, Holthuijsen LH, Booij N. A third-generation wave model for coastal regions 2: Verification. J Geophys Res 1999; 104: 7667-81.

[33] SWAN User Manual (Cycle III version 40.72AB), Delft University of Technology, Delft, 2009.

[34] Teixeira JC, Abreu MP, Guedes Soares C. Uncertainty of Ocean Wave Hindcasts due to Wind Modelling. J Offshore Mech Arctic Eng 1995; 117: 294-297.

[35] Holthuijsen LH, Booji N, Bertotti L. The propagation of wind errors through ocean wave hindcasts. J Offshore Mech Arctic Eng 1996; 118: 184-189. 
[36] Ponce de León S, Ocampo-Torres FJ. Sensitivity of a wave model to wind variability. J Geophys Res 1998; 103: 3179-3201.

[37] Ponce de León S, Guedes Soares C. Sensitivity of wave model predictions to wind fields in the Western Mediterranean sea. J Coast Eng 2008; 55: 920-929.

[38] PODAAC, Sea Winds on QuikSCAT level3 (JPL Sea Winds Project): Guide Document, USA, 2001.

[39] Holthuijsen LH, Booij N, Ris RC. A spectral wave model for the coastal zone. In: 2nd International symposium on ocean wave measurement and analysis, New Orleans, Louisiana, New York, proceedings, July 25-28, 1993, p. 630-41.

[40] Ris RC, Holthuijsen LH, Booij N. A spectral model for waves in the near shore zone. In: 24th International conference on coastal engineering, Kobe, Japan, proceedings, October, 1994, p. 68-78.

[41] Zijlema M, Van der Westhuysen AJ. On convergence behaviour and numerical accuracy in stationary SWAN simulations of nearshore wind wave spectra. J Coast Eng 2005; 52(3): 237-56.

[42] Moeini MH, Etemad-Shahidi A. Application of two numerical models for wave hindcasting in Lake Erie. J Appl Ocean Res 2007; 29: 137-45.

[43] Komen GJ, Hasselmann S, Hasselmann K. On the existence of a fully developed wind sea spectrum. J Phys Oceanogr 1984; 14: 1271-1285.

[44] Ertekin RC, Yingfan X. Preliminary assessment of the wave energy resource using observed wave and wind data. J Energy 1994; 19: 729-738.

[45] Dunnett D, Wallace JS. Electricity generation from wave power in Canada. J Renew Energy 2009; 34(1): 179-195.

[46] Archetti R, Bozzi S, Passoni G. Feasibility study of a wave energy farm in the western Mediterranean Sea: comparison among different technologies. 30th International Conference 
on Ocean, Offshore and Arctic Engineering (OMAE), Rotterdam, The Netherlands, June 1924, 2011.

[47] Babarit A, Hals J, Muliawan MJ, Kurniawan A, Moan T, Krokstad J. Numerical benchmarking study of a selection of wave converters. J Renew Energy 2012; 41: 44-63. 


\section{Figures Caption}

Fig.1. Computational area in the Caspian Sea and the location of Anzali buoy.

Fig.2. Bathymetric map of the study area.

Fig.3. Comparison of the measured and modeled: (a) significant wave height (b) wave power during the calibration period.

Fig.4. Comparison of the measured and modeled: (a) significant wave height (b) wave power during the verification period.

Fig.5. Spatial distribution of annual wave power based on SWAN hindcast results in the study area.

Fig.6. Seasonal spatial distribution of wave power based on SWAN hindcast results in the study area.

Fig.7. Location of 6 sites with high wave energy in the study area.

Fig.8. Wave power variations, site M: (a) Seasonal averages (b) Monthly averages.

Fig.9. Wave roses for two energetic months in site M: (a) January (b) February.

Fig.10. Contribution to the total annual wave energy $(\mathrm{MWh} / \mathrm{m})$ of the different sea states at site $\mathrm{M}$. 


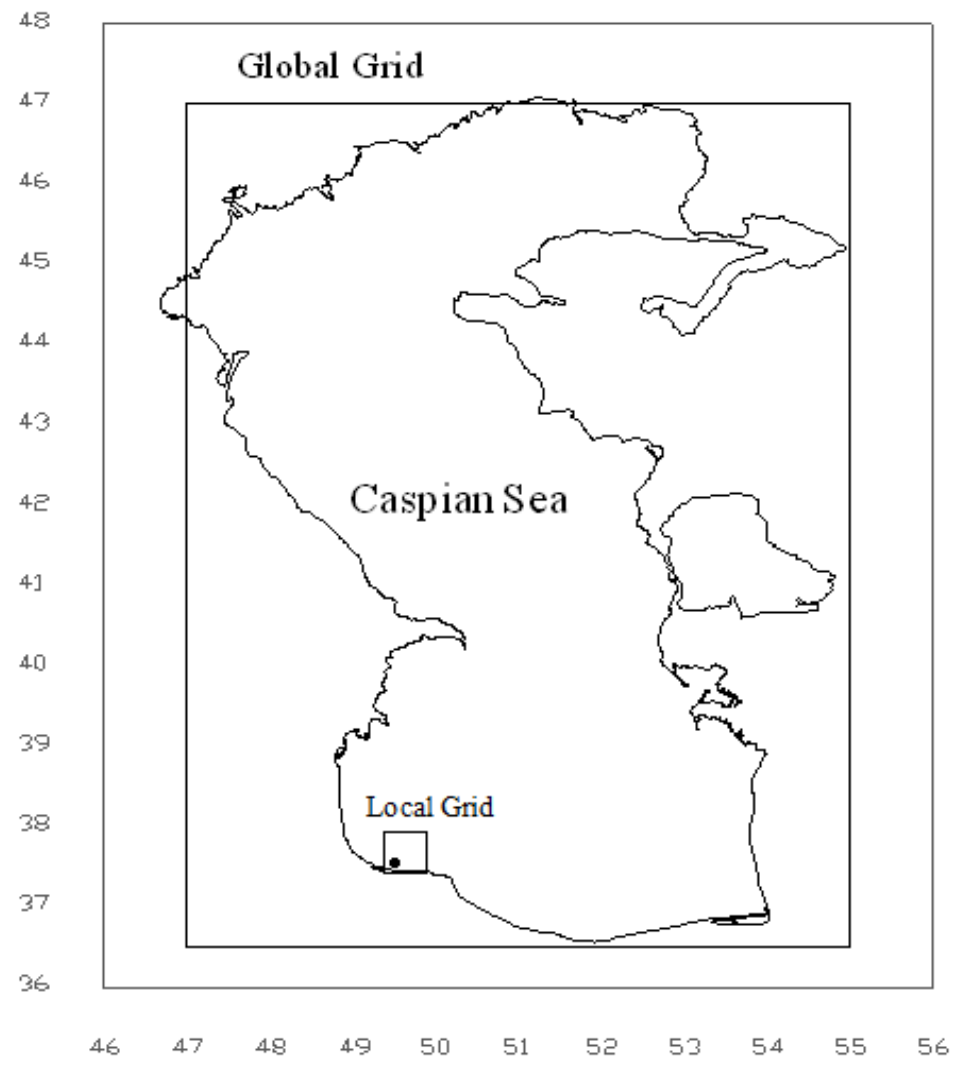

Fig.1. Computational area in the Caspian Sea and the location of Anzali buoy. 


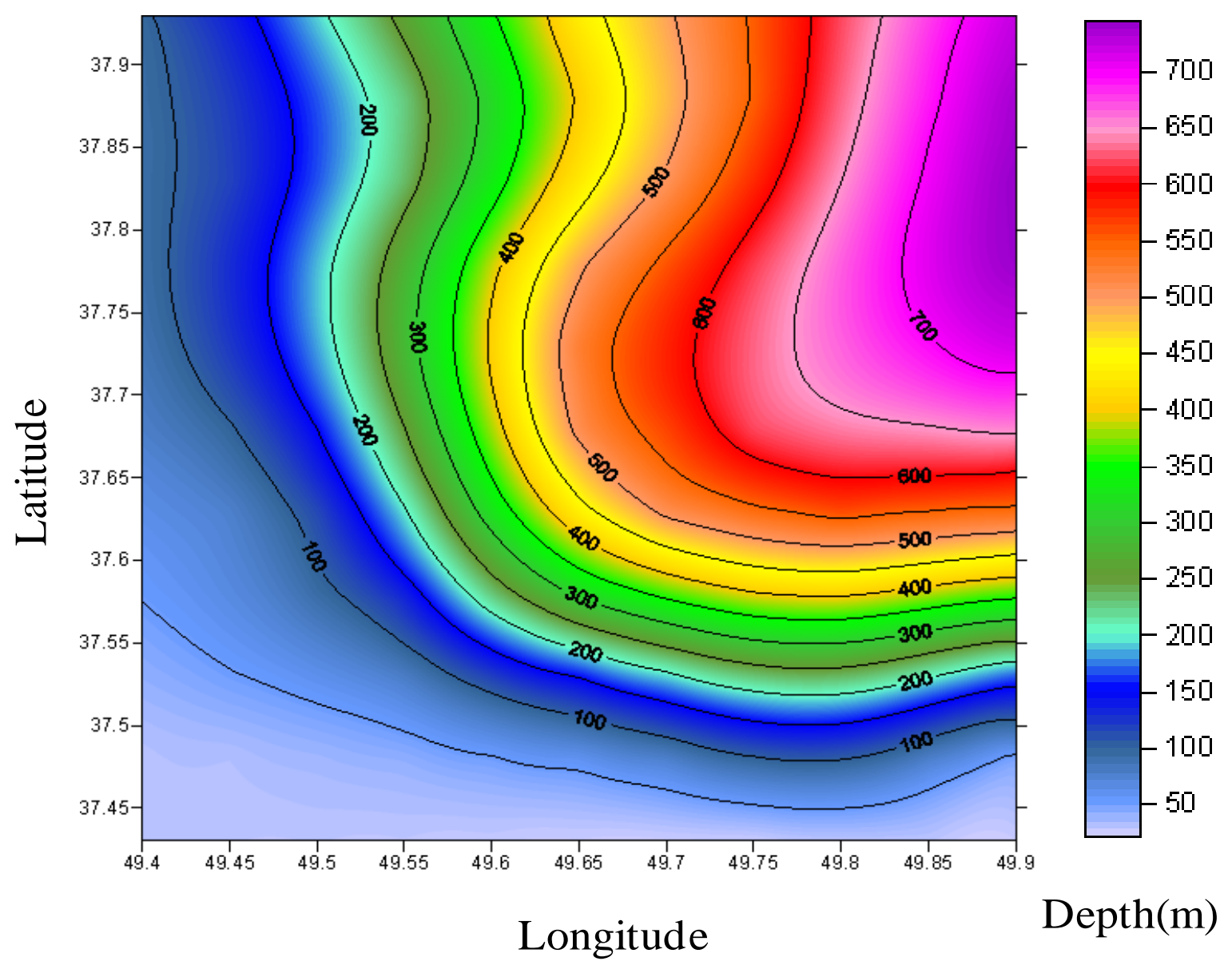

Fig.2. Bathymetric map of the study area. 

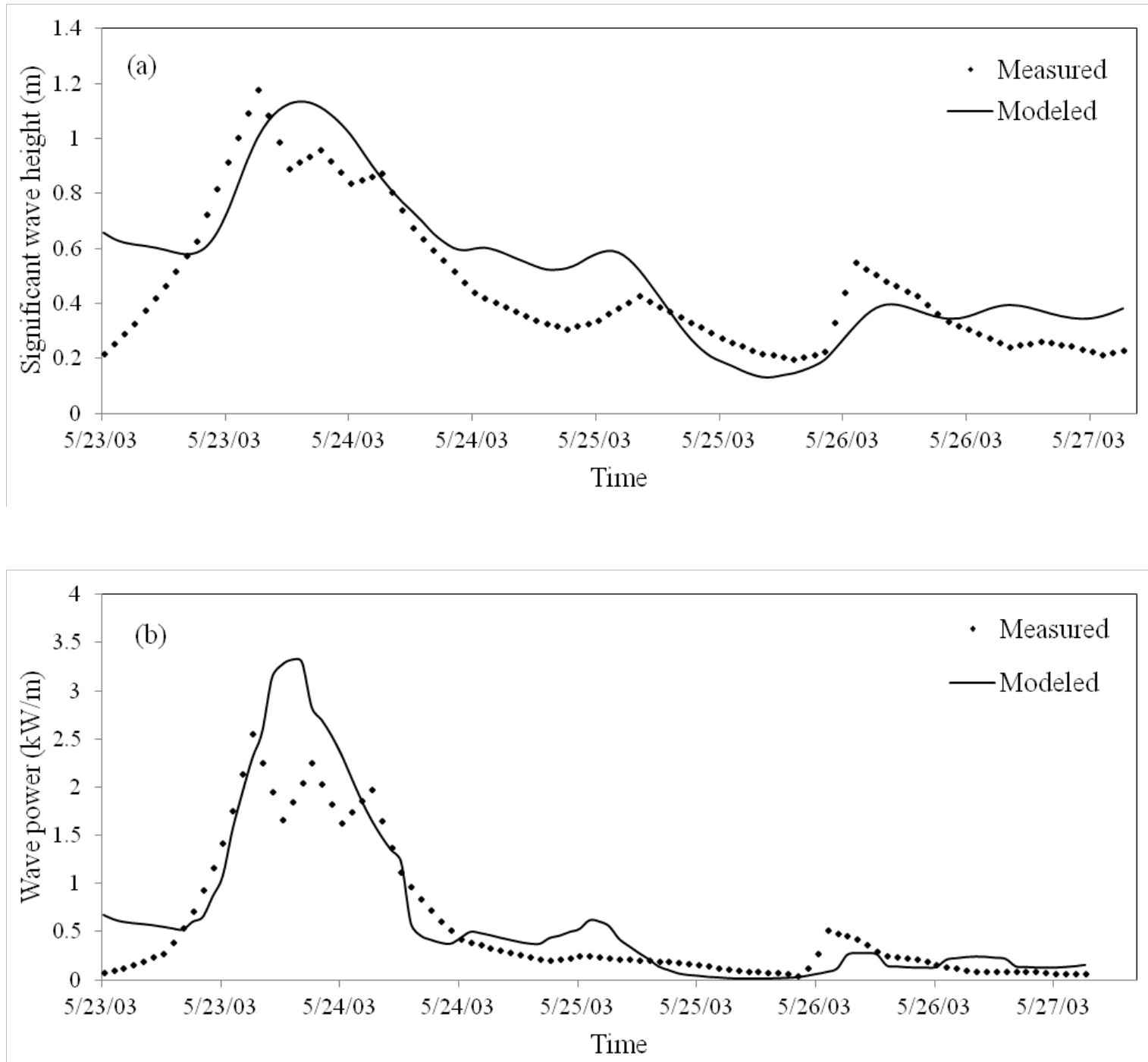

Fig.3. Comparison of the measured and modeled: (a) significant wave height (b) wave power during the calibration period. 

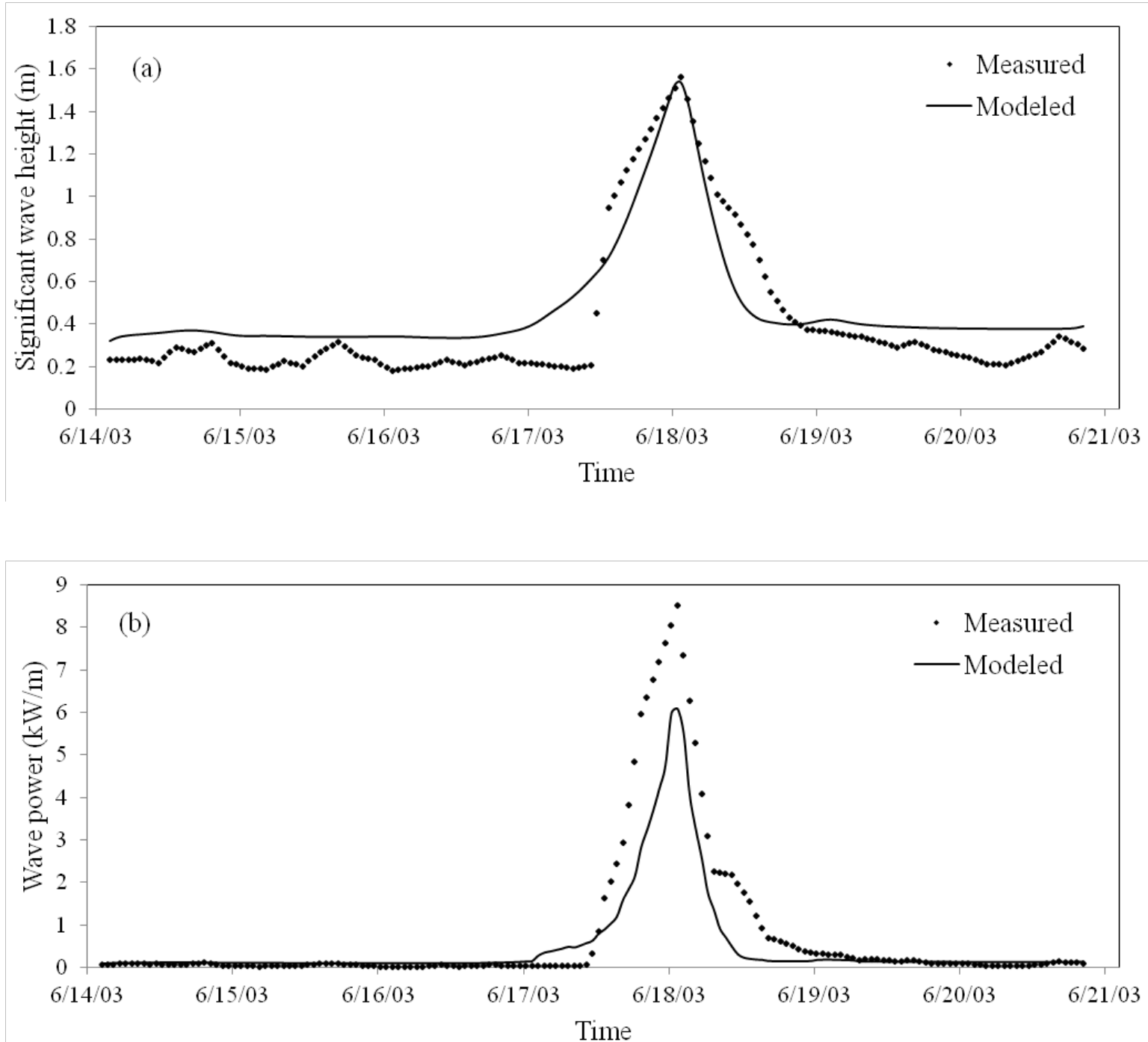

Fig.4. Comparison of the measured and modeled: (a) significant wave height (b) wave power during the verification period. 


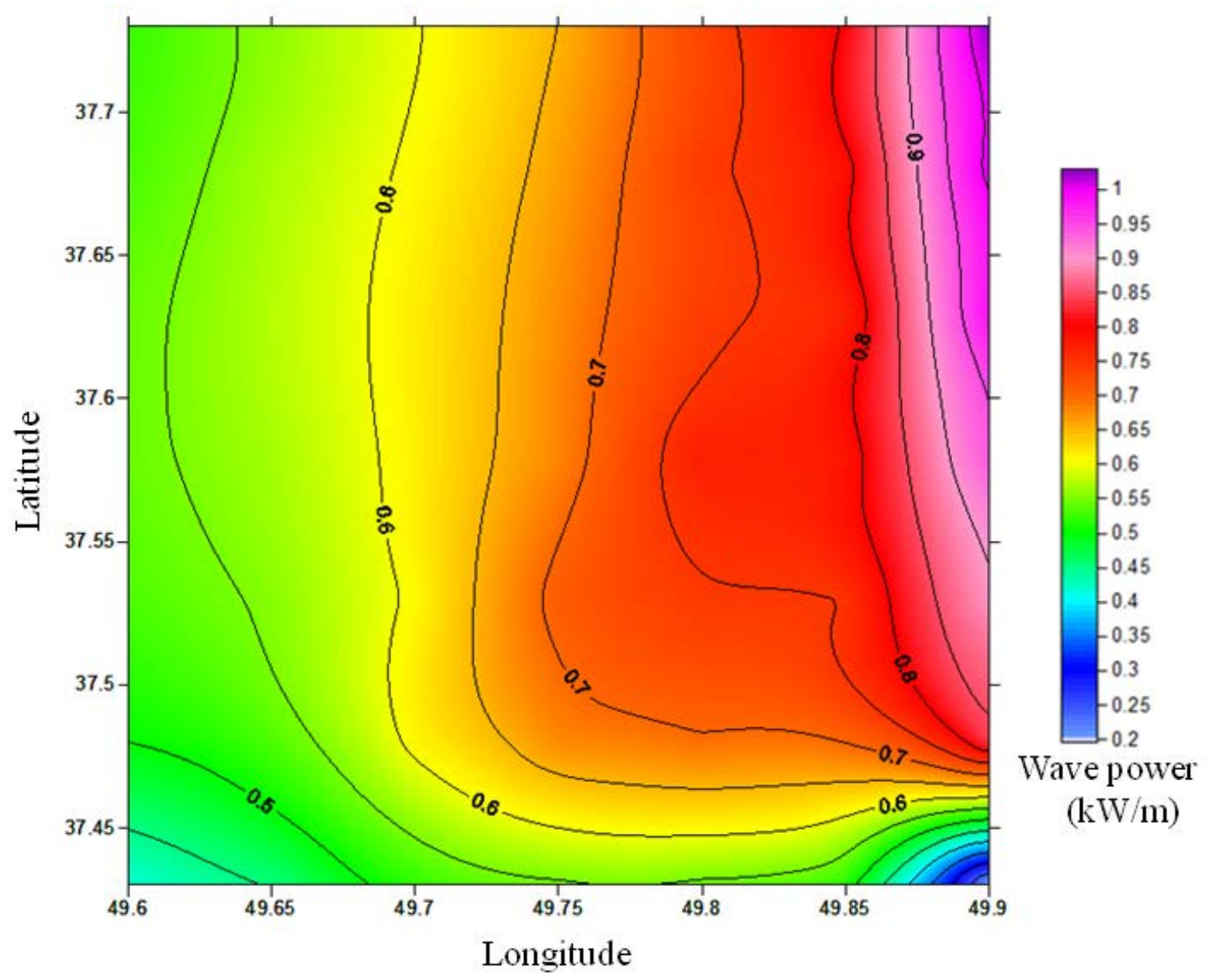

Fig.5. Spatial distribution of annual wave power based on SWAN hindcast results in the study area. 

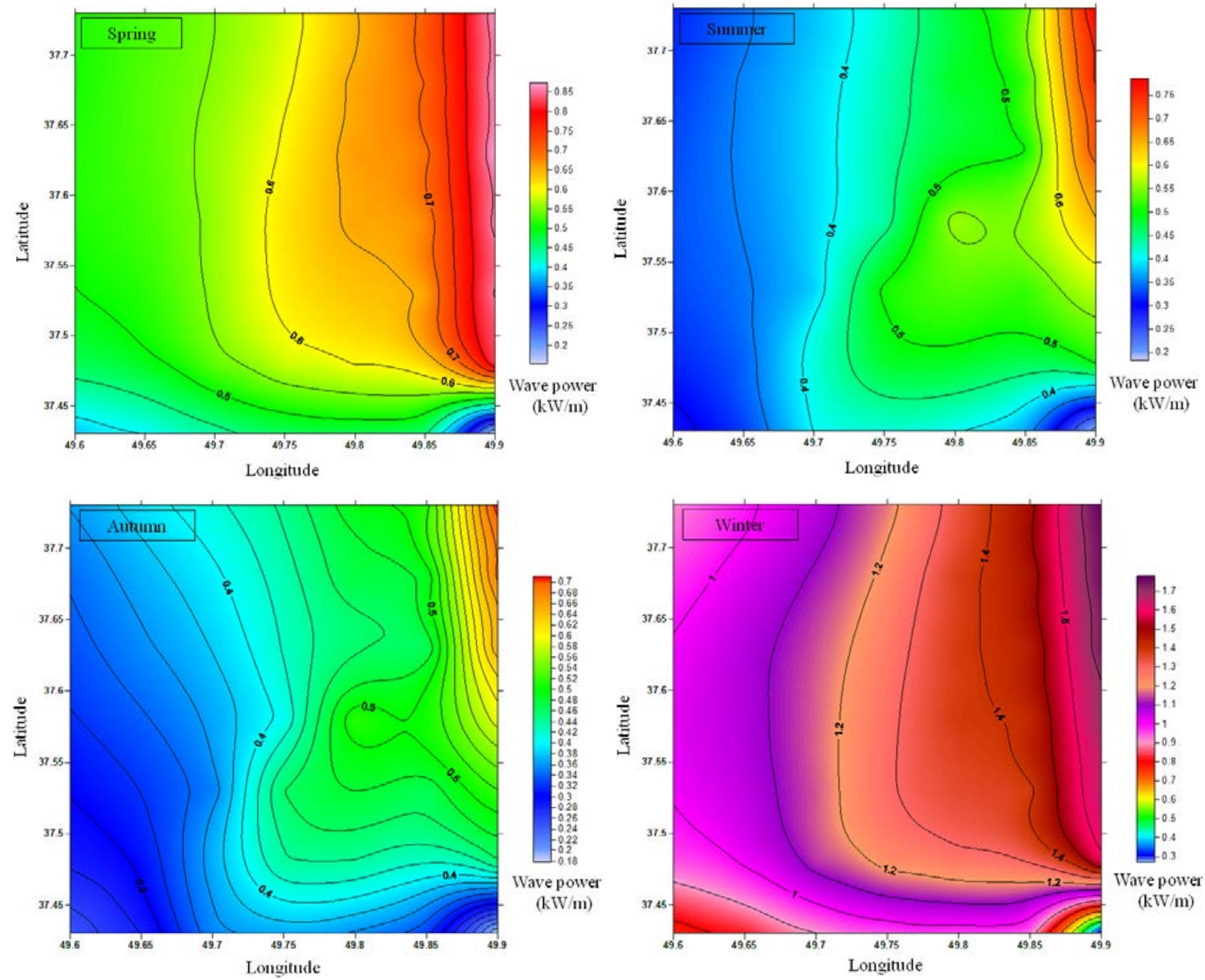

Fig.6. Seasonal spatial distribution of wave power based on SWAN hindcast results in the study area. 


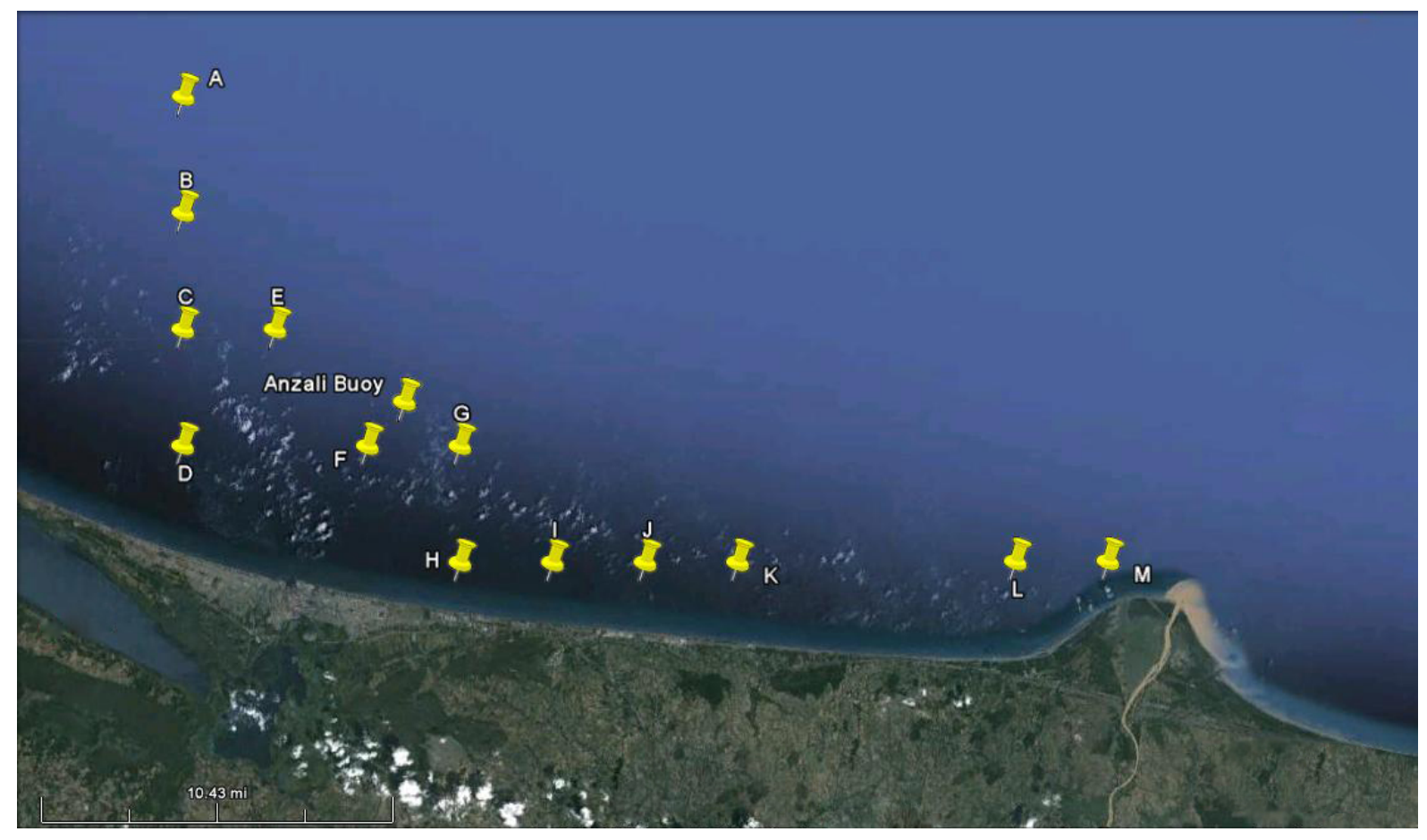

Fig.7. Location of the selected sites with high wave power in the study area. 

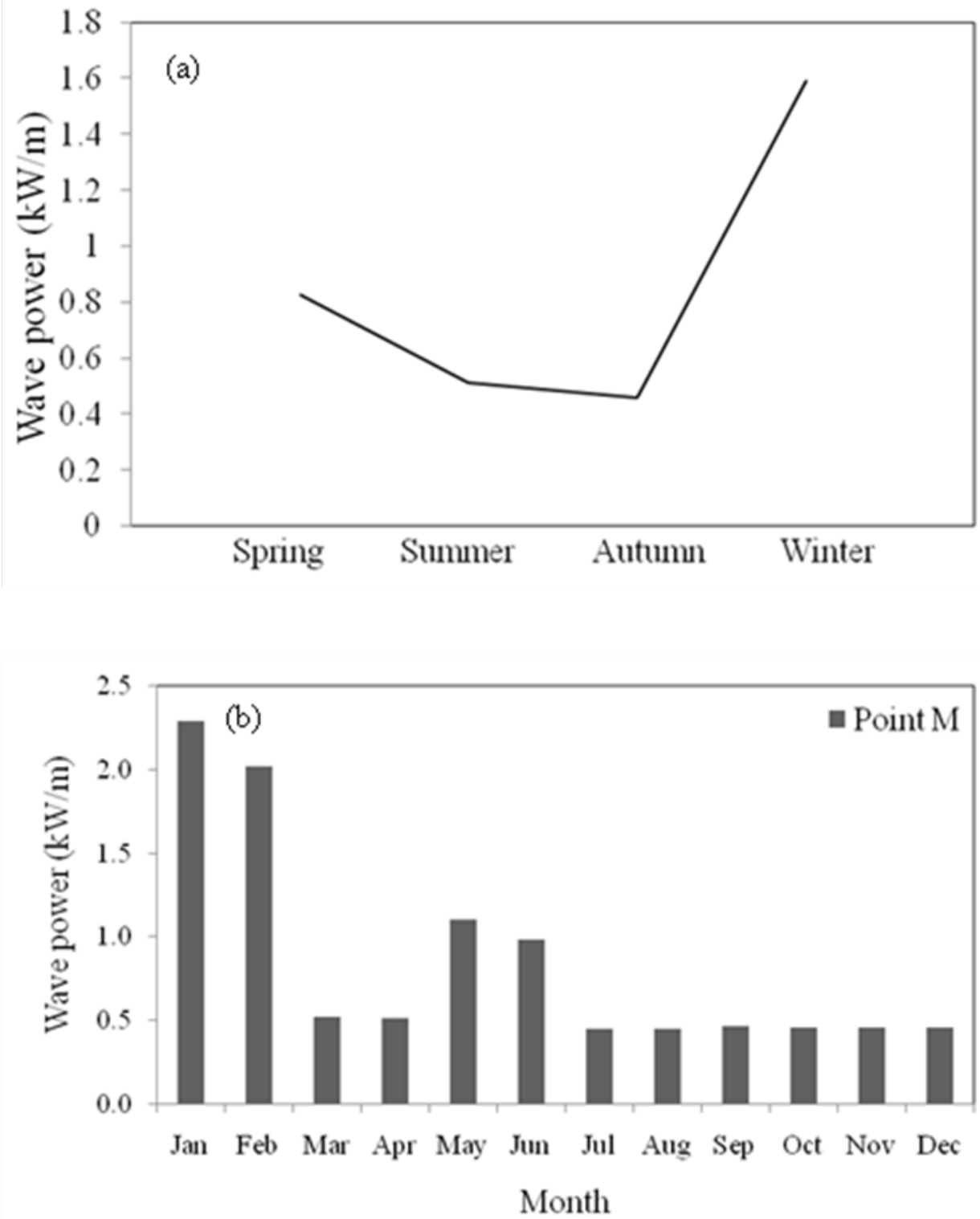

Fig.8. Wave power variations, site M: (a) Seasonal averages (b) Monthly averages. 

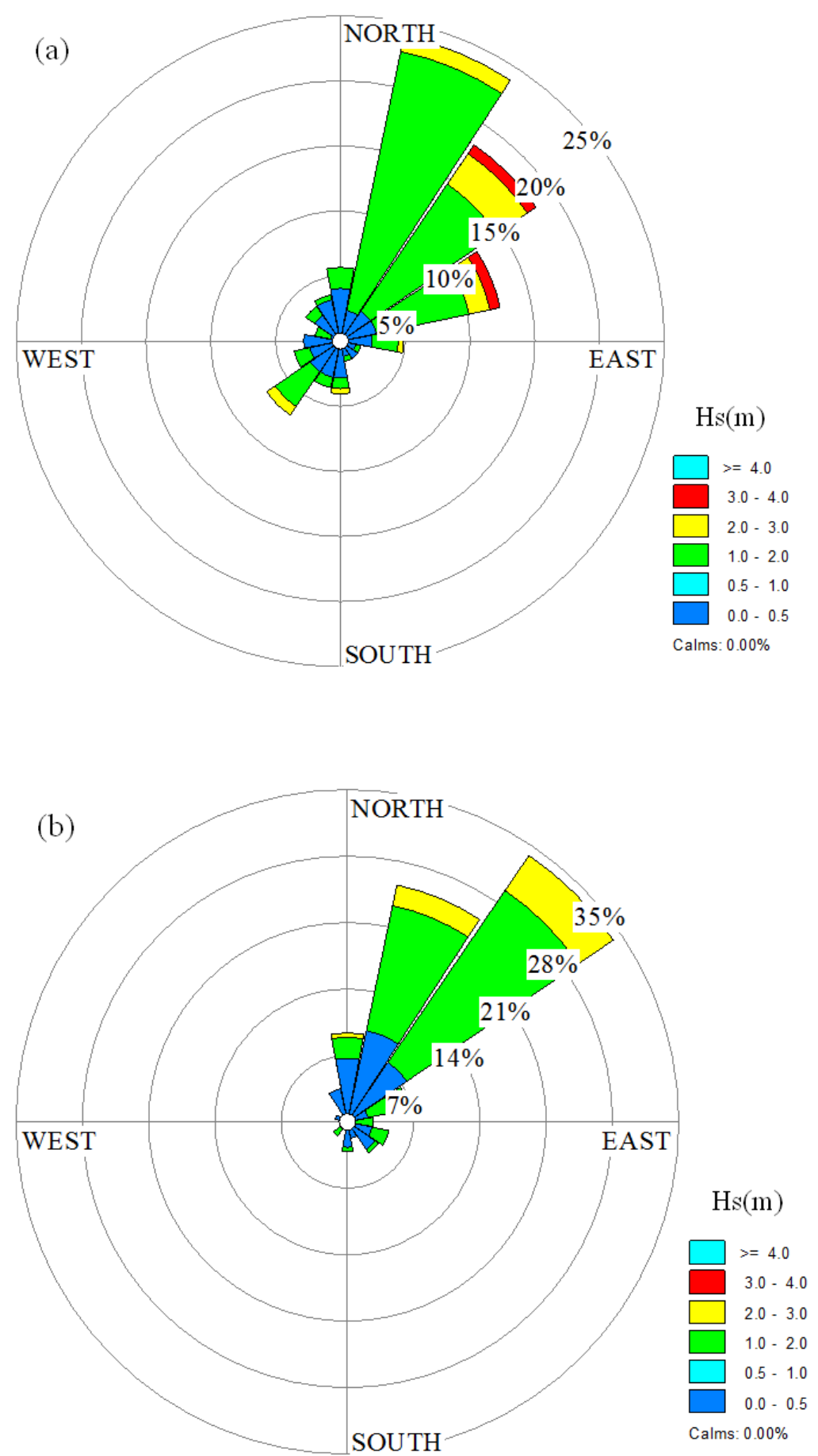

Fig.9. Wave roses for two energetic months in site M: (a) January (b) February. 


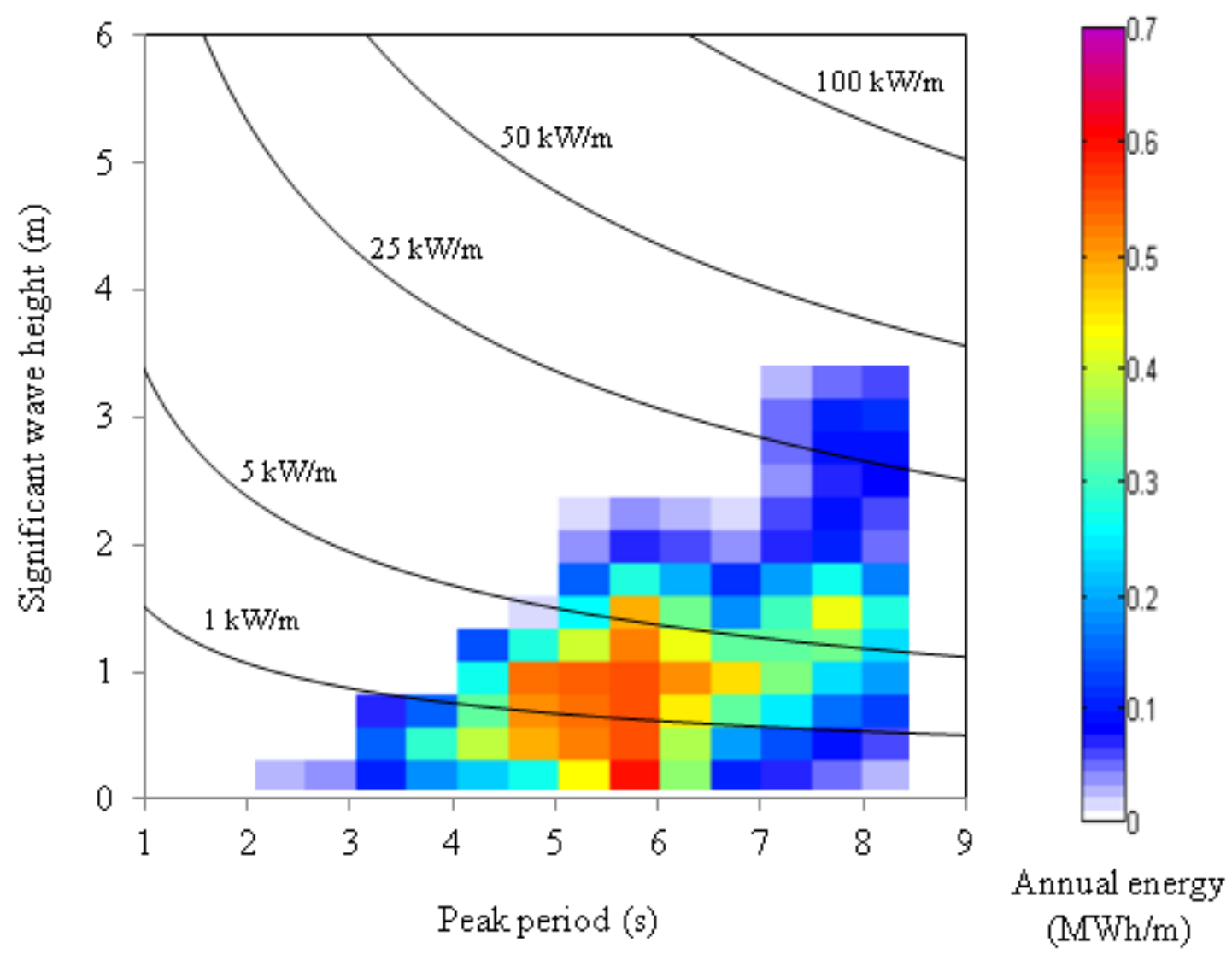

Fig.10. Contribution to the total annual wave energy $(\mathrm{MWh} / \mathrm{m})$ of the different sea states at site $M$. 
Table 1: Statistics of the wave characteristics for the calibration and verification periods.

\begin{tabular}{ccccc}
\hline \multirow{2}{*}{ Parameters } & \multicolumn{2}{c}{$H_{S}(\mathrm{~m})$} & \multicolumn{2}{c}{$T_{P}(\mathrm{~s})$} \\
\cline { 2 - 5 } & $\begin{array}{c}\text { Calibration } \\
\text { Period }\end{array}$ & $\begin{array}{c}\text { Verification } \\
\text { Period }\end{array}$ & $\begin{array}{c}\text { Calibration } \\
\text { Period }\end{array}$ & $\begin{array}{c}\text { Verification } \\
\text { Period }\end{array}$ \\
\hline Minimum & 0.20 & 0.18 & 1.89 & 2 \\
Maximum & 1.18 & 1.56 & 5.88 & 8.33 \\
\hline
\end{tabular}


Table 2: Error indices of wave parameters for both calibration and verification periods.

\begin{tabular}{ccccc}
\hline \multirow{2}{*}{ error index } & \multicolumn{2}{c}{ calibration period } & \multicolumn{2}{c}{ verification period } \\
\cline { 2 - 5 } & $\begin{array}{c}\text { Significant } \\
\text { wave height }\end{array}$ & Wave power & $\begin{array}{c}\text { Significant } \\
\text { wave height }\end{array}$ & Wave power \\
\hline Bias & 0.065 & 0.108 & 0.064 & -0.281 \\
$R$ & 0.860 & 0.915 & 0.933 & 0.969 \\
$R$ RSE & & & & 0.815 \\
\hline
\end{tabular}


Table 3: Location of the selected sites and their annual wave power, distance from coastline and water depth.

\begin{tabular}{cccccc}
\hline $\begin{array}{c}\text { Point } \\
\text { number }\end{array}$ & Longitude $\left(^{\circ}\right)$ & Latitude $\left(^{\circ}\right)$ & Depth $(\mathrm{m})$ & $\begin{array}{c}\text { Average } \\
\text { power } \\
(\mathrm{kW} / \mathrm{m})\end{array}$ & $\begin{array}{c}\text { Distance from } \\
\text { the shore }(\mathrm{km})\end{array}$ \\
\hline A & 49.40 & 37.68 & 76.00 & 0.79 & 20.74 \\
B & 49.40 & 37.63 & 62.20 & 0.79 & 15.06 \\
C & 49.40 & 37.58 & 51.40 & 0.74 & 9.63 \\
D & 49.40 & 37.53 & 39.20 & 0.71 & 4.03 \\
E & 49.45 & 37.58 & 65.00 & 0.50 & 9.82 \\
F & 49.50 & 37.53 & 59.80 & 0.51 & 6.16 \\
G & 49.55 & 37.53 & 76.80 & 0.54 & 6.87 \\
H & 49.55 & 37.48 & 39.20 & 0.49 & 1.34 \\
I & 49.60 & 37.48 & 48.20 & 0.51 & 1.90 \\
J & 49.65 & 37.48 & 56.80 & 0.55 & 2.41 \\
K & 49.70 & 37.48 & 73.19 & 0.65 & 2.65 \\
L & 49.85 & 37.48 & 74.00 & 0.75 & 3.67 \\
M & 49.90 & 37.48 & 44.00 & 0.84 & 1.13 \\
\hline
\end{tabular}


Table 4: Annual wave energy corresponding to sea states in different ranges of $H s$ and $T_{p}$, and the percentage of the accessible total energy in each interval, site $\mathrm{M}$.

\begin{tabular}{|c|c|c|c|c|c|c|c|c|c|c|}
\hline & \multirow{2}{*}{$H_{s}(\mathrm{~m})$} & \multicolumn{9}{|c|}{$T_{p}(\mathrm{~s})$} \\
\hline & & $<2$ & $2-3$ & $3-4$ & $4-5$ & $5-6$ & $6-7$ & $7-8$ & $>8$ & Total \\
\hline \multirow{2}{*}{$>4$} & $\mathrm{E}(\mathrm{kWh} / \mathrm{m})$ & 0.00 & 0.00 & 0.00 & 0.00 & 0.00 & 0.00 & 0.00 & 0.00 & 0.00 \\
\hline & $\%$ Total & 0.00 & 0.00 & 0.00 & 0.00 & 0.00 & 0.00 & 0.00 & 0.00 & 0.00 \\
\hline \multirow{2}{*}{$3-4$} & $\mathrm{E}(\mathrm{kWh} / \mathrm{m})$ & 0.00 & 0.00 & 0.00 & 0.00 & 0.00 & 0.00 & 4.00 & 5.29 & 9.29 \\
\hline & \% Total & 0.00 & 0.00 & 0.00 & 0.00 & 0.00 & 0.00 & 0.03 & 0.03 & 0.07 \\
\hline \multirow{2}{*}{$2-3$} & $\mathrm{E}(\mathrm{kWh} / \mathrm{m})$ & 0.00 & 0.00 & 0.00 & 0.00 & 2.66 & 1.47 & 6.89 & 3.82 & 14.84 \\
\hline & \% Total & 0.00 & 0.00 & 0.00 & 0.00 & 0.07 & 0.03 & 0.10 & 0.03 & 0.24 \\
\hline \multirow{2}{*}{$1-2$} & $\mathrm{E}(\mathrm{kWh} / \mathrm{m})$ & 0.00 & 0.00 & 0.00 & 19.34 & 42.72 & 26.08 & 27.21 & 12.43 & 127.78 \\
\hline & \% Total & 0.00 & 0.00 & 0.00 & 1.99 & 2.43 & 1.41 & 0.99 & 0.45 & 7.27 \\
\hline \multirow{2}{*}{$0.5-1$} & $\mathrm{E}(\mathrm{kWh} / \mathrm{m})$ & 0.00 & 0.22 & 8.10 & 18.05 & 21.93 & 7.32 & 4.06 & 1.72 & 61.40 \\
\hline & \% Total & 0.00 & 0.17 & 3.77 & 5.01 & 4.63 & 1.37 & 0.55 & 0.17 & 15.67 \\
\hline \multirow{2}{*}{$<0.5$} & $\mathrm{E}(\mathrm{kWh} / \mathrm{m})$ & 0.19 & 3.41 & 4.41 & 3.87 & 79.85 & 0.89 & 0.26 & 0.09 & 92.97 \\
\hline & $\%$ Total & 3.53 & 11.66 & 7.82 & 4.05 & 48.99 & 0.45 & 0.21 & 0.07 & 76.76 \\
\hline \multirow{2}{*}{ Total } & $\mathrm{E}(\mathrm{kWh} / \mathrm{m})$ & 0.19 & 3.63 & 12.51 & 41.26 & 147.16 & 35.76 & 42.42 & 23.35 & 306.28 \\
\hline & \% Total & 3.53 & 11.83 & 11.59 & 11.04 & 56.12 & 3.26 & 1.89 & 0.75 & 100.00 \\
\hline
\end{tabular}


Table 5: Percentage of total time in an average year of sea states in different significant wave height intervals and mean wave direction, site $\mathrm{M}$.

\begin{tabular}{|c|c|c|c|c|c|c|c|}
\hline \multirow{2}{*}{ Direction } & \multicolumn{7}{|c|}{$H_{s}(m)$} \\
\hline & $<0.5$ & $0.5-1$ & $1-2$ & $2-3$ & $3-4$ & $>4$ & Total \\
\hline $\mathrm{N}$ & 2.91 & 1.54 & 0.14 & 0.00 & 0.00 & 0.00 & 4.59 \\
\hline NNE & 16.18 & 4.94 & 2.06 & 0.00 & 0.00 & 0.00 & 23.17 \\
\hline $\mathrm{NE}$ & 42.10 & 4.29 & 3.50 & 0.07 & 0.03 & 0.00 & 49.98 \\
\hline ENE & 1.99 & 1.54 & 0.65 & 0.14 & 0.03 & 0.00 & 4.35 \\
\hline $\mathrm{E}$ & 1.06 & 0.51 & 0.21 & 0.00 & 0.00 & 0.00 & 1.78 \\
\hline ESE & 0.69 & 0.41 & 0.03 & 0.00 & 0.00 & 0.00 & 1.13 \\
\hline $\mathrm{SE}$ & 0.82 & 0.21 & 0.00 & 0.00 & 0.00 & 0.00 & 1.03 \\
\hline SSE & 0.79 & 0.07 & 0.00 & 0.00 & 0.00 & 0.00 & 0.86 \\
\hline S & 0.96 & 0.21 & 0.03 & 0.00 & 0.00 & 0.00 & 1.20 \\
\hline SSW & 0.72 & 0.14 & 0.00 & 0.00 & 0.00 & 0.00 & 0.86 \\
\hline SW & 1.41 & 0.65 & 0.51 & 0.03 & 0.00 & 0.00 & 2.61 \\
\hline WSW & 0.99 & 0.45 & 0.03 & 0.00 & 0.00 & 0.00 & 1.47 \\
\hline W & 1.23 & 0.27 & 0.00 & 0.00 & 0.00 & 0.00 & 1.51 \\
\hline WNW & 1.13 & 0.07 & 0.03 & 0.00 & 0.00 & 0.00 & 1.23 \\
\hline NW & 1.58 & 0.14 & 0.03 & 0.00 & 0.00 & 0.00 & 1.75 \\
\hline NNW & 2.19 & 0.24 & 0.03 & 0.00 & 0.00 & 0.00 & 2.47 \\
\hline Total & 76.76 & 15.67 & 7.27 & 0.24 & 0.07 & 0.00 & 100.00 \\
\hline
\end{tabular}

